\title{
STRATEGI PEMASARAN DALAM UPAYA MENINGKATKAN PENJUALAN (STUDI KASUS: PT XYZ)
}

\author{
Muhammad Ihsan \\ Program Studi Magister Manajemen Universitas Tarumanagara \\ muhammadihsan024@yahoo.com \\ Nurahma Tresani \\ Program Studi Magister Manajemen Universitas Tarumanagara
}

Masuk : 06-12-2020, revisi : 15-12-2020, diterima untuk diterbitkan : 16-12-2020

\begin{abstract}
The purpose of this study is to determine the marketing strategy of PT XYZ to increase sales. The method used in this research is descriptive using primary and secondary data which are processed based on the results of interviews with the management of PT XYZ. This research uses internal environmental analysis including Segmentation, Target and Position (STP), Marketing Function, Financial Function, Human Resource Function, Operational Function and Marketing Mix (7P), industrial environment analysis (Porter's 5 Strengths), and external environment (PESTEL). From the analysis of the company environment, it is clarified using the IE Matrix and the SWOT analysis resulting in 4 sets of alternative strategies in the SWOT Matrix. Based on data from the company's internal and external environmental factors, the IFE Matrix is 2.96 and the EFE Matrix is 3.06, then the IE Matrix is in quadrant II, where the strategic position of PT XYZ is in a position of growth and development which describes the condition of the company is growing and developing. The result of PT XYZ's SWOT quadrant is in quadrant I, where the strategy commonly used is to support aggressive growth policies.
\end{abstract}

Keywords: SWOT, IE Matrix, Marketing Mix, Marketing Strategy

Abstrak: Tujuan dari penelitian ini adalah untuk menentukan strategi pemasaran perusahaan PT XYZ dalam upaya meningkatkan penjualan. Metode yang digunakan dalam penelitian ini adalah deskriptif menggunakan data primer dan sekunder yang diolah berdasarkan hasil dari wawancara dengan manajemen PT XYZ. Penelitian ini menggunakan analisis lingkungan internal meliputi Segmentasi, Target dan Posisi (STP), Fungsi Pemasaran, Fungsi Keuangan, Fungsi Sumber Daya Manusia, Fungsi Operasional, dan Bauran Pemasaran (7P), analisis lingkungan industri (5 Kekuatan Porter's) dan lingkungan eksternal (PESTEL). Dari analisis lingkungan perusahaan, diperjelas dengan menggunakan Matriks IE dan analisis SWOT menghasilkan 4 set strategi alternatif pada Matriks SWOT. Berdasarkan data dari faktor lingkungan internal dan eksternal perusahaan, didapatkan Matriks IFE adalah 2.96 dan Matriks EFE adalah 3.06, maka Matriks IE berada di kuadran II, dimana posisi strategis PT XYZ berada pada posisi pertumbuhan dan pembangunan yang menggambarkan kondisi perusahaan sedang bertumbuh dan berkembang. Hasil kuadran SWOT PT XYZ berada di kuadran I, dimana strategi yang biasa digunakan adalah mendukung kebijakan pertumbuhan yang agresif.

Kata Kunci: SWOT, Matriks IE, Bauran Pemasaran, Strategi Pemasaran

\section{LATAR BELAKANG}

Di era globalisasi ini terdapat kemajuan yang begitu pesat terutama industri event organizer. Event organizer merupakan sebuah jasa profesional untuk menyelenggarakan suatu acara dalam ruangan maupun di luar ruangan. Segmentasi pasar event organizer sangatlah luas seperti kalangan menengah hingga kalangan atas guna mendukung suksesnya suatu acara 
sehingga dapat berjalan sesuai dengan keinginan penyelenggara acara/hajat dan berjalan sebagaimana mestinya sesuai dengan tujuan diselenggarakannya acara tersebut.

Pertumbuhan jasa event organizer di Indonesia mengalami peningkatan setiap tahunnya. Dari data Assosiasi Pelaksana dan Penyelenggara Indonesia, tercatat dari tahun 2017 yang beranggotakan lebih dari 80 pelaku bisnis event organizer perputaran uang di bisnis ini mencapai Rp. 102 milliar. Angka ini diambil hanya dari member resmi assosiasi, padahal pelaku event organizer diluar assosiasi ini sangat banyak. Setiap event organizer tentu saling berkompetisi dalam merancang strategi yang akan diterapkan dalam menjalankan usahanya. Persaingan ini sebagai suatu tantangan yang akan menjadi peluang bagi perusahaan untuk dapat mengembangkan strategi. Menyikapi persaingan yang ketat serta pertumbuhan perusahaan khususnya dibidang jasa event organizer, perusahaan dinilai penting memperhatikan strategistrategi guna menghadapi persaingan serta meningkatkan volume penjualan. Strategi-strategi bisnis yang akan diambil perlu dipertimbangkan serta disesuaikan dengan kondisi perusahaan pada saat ini. Dalam persaingan bisnis, perusahaan perlu mengetahui kekuatan dan kelemahan perusahaan itu sendiri. Hal ini sangat membantu perusahaan dalam mengenali diri, serta memanfaatkan peluang dan meminimalisir ancaman yang ada dalam persaingan pasar industri event organizer itu sendiri. Berdasarkan permasalahan tersebut diatas, maka dilakukan penelitian ini yang difokuskan pada kajian untuk menggambarkan Strategi Event Ogranizer PT XYZ dalam menggerakkan bisnis industri Event Organizer. Dengan rumusan permasalahan penelitian yaitu "Bagaimana strategi pemasaran PT XYZ dalam upaya meningkatkan penjualan".

\section{TINJAUAN LITERATUR}

Menurut Pearce dan Robinson (2007), manajemen strategi didefinisikan sebagai satu set keputusan dan tindakan yang menghasilkan formulasi dan implementasi rencana yang dirancang untuk meraih tujuan suatu perusahaan. David (2012) menyatakan bahwa manajemen strategis dapat didefinisikan sebagai seni dan pengetahuan dalam merumuskan, mengimplementasikan, serta mengevaluasi keputusan-keputusan lintas-fungsional yang memampukan sebuah organisasi mencapai tujuannya. Tingkat-tingkat strategi menurut Hunger dan Wheelen (2001, p. 26), terdapat tiga tingkatan strategi dalam perusahaan, yaitu: Strategi Korporat (Perusahaan), Strategi Bisnis, dan Strategi Fungsional.

Dalam hal ini manajemen strategi mencakup aliran keputusan, cara-cara membentuk strategi, membuat keputusan desain serta program perusahaan dan mengembangkan strategistrategi yang efektif (Amirullah, 2015, pp. 5-7). Menurut Kotler dan Keller (2007), pemasaran secara sederhana adalah yang mengatur relasi menguntungkan dengan konsumen. Tujuan dari pemasaran adalah menciptakan nilai untuk konsumen dan untuk menangkap nilai dari konsumen atau mendapat timbal balik dari konsumen. Menurut Cravens dan Piercy dalam Wibowo dan Priansa (2017), Strategi Pemasaran merupakan proses market-driven dari pengembangan strategi yang mempertimbangkan perubahan lingkungan dan kebutuhan untuk menawarkan superior customer value. Marketing mix untuk jasa dijabarkan dengan metode 7P, yaitu product, price, place, promotion, physical evidence, people dan process (Kotler \& Keller, 2012). David (2012) menjabarkan kekuatan-kekuatan analisa eksternal utama dapat dibagi menjadi lima kategori luas: (1) kekuatan ekonomi; (2) kekuatan sosial, budaya, demografis, dan lingkungan; (3) kekuatan politik, pemerintahan, dan hukum; (4) kekuatan teknologi; dan (5) kekuatan kompetitif. Menurut Porter (2000, p. 6), analisis Five Forces Porter (Model Lima Kekuatan Porter) adalah pendekatan yang digunakan secara luas untuk mengembangkan strategi di banyak industri. Menurut Pearce dan Robinson (2007), lingkungan internal adalah semua faktor yang berada didalam kendali perusahaan yang harus dikelola dan diatur untuk dapat mencapai tujuan perusahaan. Kotler dan Keller (2012) mengemukakan bahwa analisis SWOT adalah evaluasi terhadap keseluruhan kekuatan, kelemahan, peluang dan ancaman. Menurut David (2009), matrik SWOT adalah sebuah alat untuk mengidentifikasi kecocokan 
suatu kepentingan yang membantu manajer mengembangkan empat tipe strategi: SO (kekuatan-peluang), WO (kelemahan-peluang), ST (kekuatanancaman), dan WT (kelemahanancaman). Mencocokkan faktor eksternal dan internal kunci adalah bagian tersulit dalam mengembangkan matrik SWOT.

\section{METODOLOGI}

Dalam penelitian ini, peneliti akan mendapatkan data deskriptif mengenai kondisi internal dan eksternal saat ini berupa kata-kata tertulis yang merupakan hasil wawancara dengan pemilik serta karyawan dari PT XYZ. Data deskriptif juga diperoleh dari studi literatur media massa seperti koran dan internet untuk mengetahui kondisi eksternal yang mempengaruhi strategi PT XYZ. Selain melakukan proses pengumpulan data, maka data yang diperoleh dilakukan analisis data untuk dapat digunakan pada proses selanjutnya. Metode untuk analisis data antara lain: Analisis Internal perusahaan, Analisis Eksternal perusahaan, Analisis SWOT dan bauran pemasaran 7P sebagai perumusan strategi pemasaran.

\section{GAMBARAN UMUM PT XYZ}

PT XYZ adalah perusahaan bisnis yang bergerak dalam bidang penyedia jasa event organizer, berdiri sejak tahun 2005 dan sudah berpengalaman dalam menangani event-event besar perusahaan ataupun peresmian program dan fasilitas umum dari pemerintahan. Beberapa event yang pernah ditangani seperti Ulang Tahun Perusahaan Jasa Raharja, Gathering Perusahaan BNI Syariah, Peresmian Jalan atau Akses Tol, Koordinator Presiden RI dan lainlain.

\section{HASIL DAN PEMBAHASAN}

Analisis yang didapat berdasarkan faktor kekuatan, kelemahan, ancaman dan peluang dari PT XYZ yang mana dari faktor tersebut mendapatkan strategi-strategi yang dapat digunakan oleh PT XYZ yaitu:

1. Mempertahankan kinerja perusahaan dan membuka kantor cabang dikota besar agar kegiatan promosi meluas

2. Aktif dalam kegiatan pemasaran atau promosi di media digital

3. Memanfaatkan media sosial atau digital marketing untuk kegiatan promosi

4. Menjaga hubungan baik dengan klien dan memberikan kesan pertama yang baik dalam menangani event klien

5. Menjalin kerja sama dengan perusahaan lain untuk menambah pangsa pasar

6. Peningkatan kualitas pelayanan melalui pendekatan kreatifitas dan inovasi

Hasil dari matriks EFE dan IFE menjadi tolak ukur pada matriks IE untuk menentukan posisi perusahaan. Berdasarkan data penelitian ini, Matriks IFE adalah 2.96 dan Matriks EFE adalah 3.06, maka Matriks IE berada di kuadran II, dimana posisi strategis PT XYZ berada pada posisi Growth and Build yang menggambarkan kondisi perusahaan sedang bertumbuh dan berkembang. Berdasarkan hasil kuadran yang didapat dari posisi perusahaan PT XYZ berada di kuadran 1 bahwa PT XYZ berada dalam situasi menguntungkan. PT XYZ memiliki peluang dan kekuatan sehingga dapat memanfaatkan peluang yang ada. Strategi yang harus diterapkan dalam kondisi ini adalah mendukung kebijakan pertumbuhan yang agresif. Strategi Strength-Opportunity (SO) dapat menjadi strategi alternatif yang sebaiknya dilakukan dengan kondisi PT XYZ saat ini.

Strategi pemasaran alernatif yang dapat dijalankan oleh PT. XYZ untuk meningkatkan volume penjualan meliputi:

1. Mempertahankan kinerja perusahaan dan membuka kantor cabang dikota besar agar kegiatan promosi meluas

2. Aktif dalam kegiatan pemasaran atau promosi di media digital 
3. Melakukan pelatihan digital marketing seperti penggunaan Adsense, Algoritma Media Sosial dan sebagainya

\section{DAFTAR PUSTAKA}

Amirullah. (2015). Manajemen strategi teori-konsep-kinerja (1st ed.). Mitra Wacana Media. David, F. R. (2009). Manajemen strategis konsep (Buku 1). Salemba Empat.

David, F. R. (2012). Manajemen strategis konsep. Salemba Empat.

Hunger, J. D., \& Wheelen, T. L. (2001). Manajemen strategis. Andi.

Kotler, P., \& Keller, K. L. (2007). Manajemen pemasaran (12th ed.). PT Indeks Kelompok Gramedia.

Kotler, P., \& Keller, K. L. (2012). Marketing management (14th ed.). Pearson Education, Inc. Pearce, \& Robinson. (2007). Manajemen Strategi. Salemba Empat.

Porter, M. E. (2000). Strategi bersaing. Erlangga.

Wibowo, L. A., \& Priansa, D. J. (2017). Manajemen komunikasi dan pemasaran. Alfabeta CV. 